\title{
Editorial
}

\section{In memoriam Andoni Garritz, profesor humanista}

\author{
Gisela Hernández Millán’
}

Agradezco a la revista Tecné, Episteme y Didaxis la oportunidad de escribir algunas palabras en memoria de Andoni, en este número multitemático, que contiene diferentes artículos en educación de ciencia, tecnología y matemáticas, que van desde el uso didáctico de estrategias inductivas, pasa por los modelos y la modelización en la historia de las ciencias, y por la competencia comunicativa del inglés, sigue con el desarrollo de los conocimientos sobre los estudiantes durante las experiencias en el practicum y termina con el conocimiento didáctico del contenido durante la enseñanza de la fuerza eléctrica en bachillerato.

Conocí a Andoni hace más de cuarenta años, cuando los dos realizábamos estudios de maestría. Fue entonces cuando reparé en su enorme generosidad. Recuerdo que le pregunté si conocía algún material donde se explicara de manera sencilla el tema de la radiactividad. Al día siguiente, llegó con un documento y me dijo: "Esto te puede servir. Te lo encargo mucho, es la única copia que tengo y está por publicarse". iMe prestaba la única copia que tenía, de un documento que recién había escrito y que aún no se publicaba! Detalles como este, le conocí muchos durante todos estos años en los que tuve la oportunidad de compartir con él diversos proyectos y actividades.

En sus años de estudiante, le tocó vivir el movimiento estudiantil de 1968 y fue encarcelado por unos días en "el palacio negro de Lecumberri", de donde salió el 20 de septiembre de ese mismo año y, como él mismo señalaba, este hecho marcó su vida.

La tesis con la que obtuvo el título de ingeniero químico en 1971 se llamó: "Algunas consideraciones sobre la ciencia y la actividad científica en el ámbito económico", lo que demuestra su interés en los aspectos sociales y económicos y refleja, de alguna manera, las inquietudes, producto seguramente de haber vivido el movimiento estudiantil y sufrido el aplastamiento, la derrota y la cárcel, aunque fuera solamente por unos pocos días. (Pessoa de Carvalho, Cachapuz \& Gil-Pérez, 2012).

Su labor como docente se inició en 1971, un año antes de titularse de lngeniero químico, con el promedio más alto de su generación y en donde además 
obtuvo mención honorífica. Dos años después, obtuvo la maestría y en 1977, el doctorado, con el tema: "La partición celular del espacio en dispersión múltiple. Modelo de átomo renormalizado para simular ferromagnetismo". En este campo publicó varios artículos, en revistas científicas como el International Journal of Quantum Chemistry.

Fue coautor, junto con Diana Cruz y José Antonio Chamizo, del libro Estructura atómica. Un enfoque químico. Durante ese proceso de escritura, su interés en la química cuántica se fue transformando poco a poco en un interés en la docencia y en la educación, para convertirse, finalmente, como él mismo lo decía, en profesor humanista.

Sin duda, uno de sus más caros proyectos es la revista Educación Química, "la mejor revista del Universo", como él la llamaba, cuyo número cero apareció en junio de 1989 y que cumple ya 27 años. Durante todo este tiempo, Andoni, siempre creativo y entusiasta, diseñó y puso en marcha distintas actividades y modalidades para la revista, algunas de las cuales menciono a continuación.

Para celebrar los aniversarios importantes, se publicaron, además de los números ordinarios, uno o dos extraordinarios con autores invitados, de reconocido prestigio internacional. Se editaron diferentes números temáticos, relacionados con el proceso de enseñanza-aprendizaje: evaluación, trabajos prácticos, concepciones alternativas, cambio conceptual, argumentación, entre otros, que han sido — tengo la seguridad_ _ una fuente de consulta importante para los educadores de la química.

Cabe mencionar que a Andoni le interesaba mucho mantener una relación cercana con los estudiantes, que finalmente son nuestra razón de ser. En este sentido, desde la revista se organizaron algunos concursos. Aquí hablaré solo de uno de ellos, que llevó por nombre "Experimento, Descubro y Aprendo", y en el que participaron más de 400 estudiantes de niveles medio superior y superior, para contestar a la pregunta ¿̇ué le pasa al aceite cuando se calienta? Viene a mi memoria la algarabía y el entusiasmo de los alumnos, así como la seriedad con la que tomaron el evento. Organizados en equipos, los jóvenes llenaron los laboratorios de la Facultad y empezaron a trabajar para contestar a la pregunta que se les había formulado. Tomaron distintos caminos, hicieron diferentes acercamientos al problema y obtuvieron muy distintas respuestas.

Sobra decir que los profesores que participaron como jurados mostraron un gran compromiso y dedicación, al observar el trabajo de los equipos y al revisar los escritos y las grabaciones. Para nosotros, fue una sorpresa encontrar respuestas tan diversas pero significativas para los alumnos, algunas correctas desde el punto de vista científico, otras muy alejadas de la explicación que da la ciencia, pero eso sí, repito, significativas para ellos. De aquí surgió en muchos de nosotros, hace ya más de veinte años, el interés por incursionar en el campo de la investigación educativa, de manera más formal, empezando a familiarizarnos con términos como el de concepciones alternativas o ideas previas, muchas de las cuales se hicieron evidentes al revisar las respuestas obtenidas en este concurso. 
Años después, Andoni escribió:

Educación Química es una revista académica que aspira a llenar el vacío de comunicación y expresión que existe entre los profesores, los estudiantes y los investigadores de las ciencias naturales y de la educación química, en particular, con el objetivo de aplicar en la clase de todos los días los hallazgos de la investigación educativa química y el conocimiento pedagógico del contenido químico de profesores sobresalientes.

Considero que Educación Química está cumpliendo con sus aspiraciones y ha llegado a ser un referente para profesores de varias partes del mundo, pero sobre todo de lberoamérica.

Tuvo varios puestos académico-administrativos, y fue director de la Facultad de Química de la unam, de 1993 a 1997, periodo en el que dio un gran impulso al mejoramiento de la enseñanza, tanto en el nivel universitario como en el bachillerato. Puso en marcha varios programas, uno de los cuales incluía el intercambio de profesores con universidades de otras partes del mundo.

A partir de 1997, cuando terminó su periodo como director, decidió dedicarse a la docencia y a la investigación en este campo. A partir de entonces, sus investigaciones se publicaron en revistas como el Science Education, el Journal of Research in Science Teaching, o el Journal of Chemical Education y ya no más en el International Journal of Quantum Chemistry o el Journal of the American Chemical Society.

Sus estudios en el área de la didáctica y la pedagogía se manifiestan en el enfoque de su segundo libro, dirigido al bachillerato, Química (Garritz \& Chamizo, 1994), así como en el tercero, Química universitaria (Garritz, Gasque \& Martínez) en los que introduce el enfoque cts, entre otras cosas.

Cabe destacar que durante diez años realizó investigaciones educativas sobre el "conocimiento pedagógico del contenido" (срc) en temas como la reacción química, la estequiometría, los ácidos y bases, campo en el que es reconocido internacionalmente. También fue un estudioso de otros aspectos del proceso de enseñanza-aprendizaje, como la afectividad en el aula y la psicología en la docencia de la química. Cito sus propias palabras al referirse a su actividad docente: "me siento como pez en el agua, con mucha libertad, imaginación y felicidad; aprendiendo más cada día sobre ese tema tan difícil: cómo enseñar".

Termino diciendo que quienes tuvimos la oportunidad de estar cerca de Andoni, lo recordaremos siempre como un líder dispuesto al diálogo, inteligente, creativo, alegre y generoso, un gran amigo y un extraordinario educador que deja encendida la luz de su invaluable legado para los educadores de la química.

\section{Referencia bibliográfica}

Pessoa de Carvalho, A. M.; Cachapuz, A. F. \& Gil-Pérez, D. (eds.). (2012). O ensino 